\title{
Re-solving Extended Expected Marginal Seat Revenue Model Using Stochastic Approach
}

\section{Martin PETRICEK ${ }^{1}$, Stepan CHALUPA $^{2^{\star}}$, Jan MACE ${ }^{3}$, Ivo STRAKA ${ }^{4}$}

\author{
${ }^{1}$ Rector, Institute of Hospitality Management in Prague, Prague, Czech Republic, Email: petricek@vsh.cz, \\ ${ }^{2}$ PhD candidate, Department of Information Technologies, University of Hradec Kralove, Hradec Kralove, Czech Republic, \\ Email: chalupa@vsh.cz, \\ ${ }^{3}$ The Vice-Rector for Study, Institute of Hospitality Management in Prague, Prague, Czech Republic, Email: mace@vsh.cz \\ ${ }^{4}$ Assistant Professor, Department of Economy and Economics, Institute of Hospitality Management in Prague, Prague, \\ Czech Republic, Email: straka@vsh.cz \\ * Corresponding Author
}

\begin{abstract}
Received: 19.11.2021 Accepted: 24.12.2021 Published: 01.02.2022 DOI: 10.47750/QAS/23.186.19
\end{abstract}
\begin{abstract}
This paper discusses the problem of hotel room sales, emphasizing the allocation of a specific amount of rooms for predefined market segments using the extension of the Expected Marginal Seat Revenue model, which can be perceived as one of the crucial activities in modern revenue management. The proposed extension of this model can improve data-based decision-making quality and the service provider's overall performance. This model uses stochastic non-linear programming to solve the problem of room allocation for the market segment and deals with the booking limits to help decide whether to accept or decline the booking request based on the behaviour of selected market segments or the expected current state of available capacities and other elements. To extend the model to fit better the managerial decision-making, the factors of no-shows and cancellations are implemented. The proposed model should be used to strengthen the quality of revenue management-focused decisions mainly focused on dynamic pricing, and the room allocation is omitted. The model respects the need for a more comprehensive perception of the problem and contains data-based factors like quantifying customer (or customer segment) behaviour and no-shows and cancellations that affect the selling strategy.
\end{abstract}

Keywords: Revenue Management, Non-linear Programming, Marginal Revenue

\section{Introduction}

Revenue management can be described as a process of proper capacity allocation to the right customers (or customer segments) at the right price while reaching the optimal revenue (and profit in modern perception of the revenue management) through the right distribution channel with the suitable distribution policy at the right time(Denizci Guillet, 2020). This broad perception of revenue management leads the researchers to partially examine the whole revenue management concept while stressing out the most important activities like business analysis, development of dynamic pricing strategies, demand forecasting, market modelling, inventory allocation and optimization, booking restrictions, and channel management and overall performance evaluation. (Noone et al., 2011)

The concept of quality in connection to revenue management is commonly connected to the topic of product versioning and service quality (Ivanov, 2014; Mitra, 2007; Mohsin, 2008; Ortega, 2016), service management quality (Ortega, 2016), quests perception of services quality (Denizci Guillet \& Mohammed, 2015), quality of revenue management decisions in pricing, capacity allocation, overbooking (Chiang et al., 2006), data quality as in input for precise forecasts and decision making (Vinod, 2004), forecasting quality
(Koupriouchina et al., 2014; Pereira, 2016; Vulcano et al., 2009), and the implementation of revenue management processes within business operation with emphasis on total quality management (Cross, 1997).

Revenue management is highly linked to quality, while the revenue managers must deal with the profit optimization from various points of view while maintaining high quality of services and their management and decision. The previously mentioned brief overview shows the topics of interest in modern revenue management and their connection to quality control on various levels. The researchers are developing new methods and approaches towards securing a high level of service quality and optimal profit level. On the other hand, the practitioners, the revenue managers, commonly use their tacit knowledge and intuition to make the decisions while omitting the availability of the data and the methods/tools for their processing. This creates a disparity between the researchers and practitioners, and the results of current research should provide relevant results that the revenue managers would understand. Thus the research results must be transferred to action to by valuable (Ivanov et al., 2021; Studnička \& Plzáková, 2017).

To understand the current need of revenue managers, some articles are dealing with the issues of data quality and their use in high-quality forecasting (Fjälmann, 2021), quality of 
revenue management systems (Verot, 2021), and the concept of quality in decision within capacity allocation and pricing (Kapichin, 2021).

This paper focuses on improving quality in decisions connected to capacity allocation, discusses Expected Marginal Seat Revenue models, and represents an extension of this model and a subsequent solution with the use of non-linear programming in the accommodation services sector within the revenue management issue. The Expected Marginal Seat Revenue (EMSR) models are still an essential building block for applications of the so-called booking limits in the services sector. The so-called booking limits are essentially a problem to implement individual incoming bookings to decide whether to accept or reject them based on a known pattern of consumer behaviour or the expected current state of available capacities and other elements, respectively. When working with the booking limits, it is necessary to work with the willingness to pay (WTP), which is usually applied by the probability distribution of demand for individual segments. Such company behaviour aims to maximize revenues from realized bookings.

\section{Literature Review}

The essential starting point for Booking Limits is Littlewood's rule and subsequently the Expected Marginal Seat Revenue (EMSR) models. At present, these models are mainly applied in the aviation industry(Gönsch et al., 2013; Gosavi et al., 2006) either in their original or modified form. Another model application can be introduced by Joshi and Lohiya(2017) using booking seats in entertainment. Rieger (2015) also lists a similar application. Buesing et al. (2019) compare EMSR models with a fundamental approach to overbooking. EMSR models are also applied in new algorithmic approaches. For example, Lawhead and Gosavi (2019) use the EMSRb version to apply their algorithm, which brings usage with Reinforcement Learning. However, the output is still based on the original model and is therefore only a new way of calculating the same solution. Another solution was created, for example, by Vulcano et al. (2010). Ko (2019) uses a methodological solution for EMSR models in the aviation industry that uses a meta-heuristic calculation approach. We can also find sub-applications of fuzzy logic for problem-solving (Teodorovic et al., 2002), but they have not been further developed.

An extension of the basic EMSR model can be found in the study by Tavana and Weatherford (2017). Their approach works with the assumption that bookings do not come at random but that consumers behave differently at specific time horizons and can be divided into several booking periods. They assume that different segments change their preferences over time. The conclusion of the model sets higher booking limits for consumers with an immense willingness to pay. The approach of the solution is based on linear programming. On the other hand, simplistic approaches to the model can also be found. Ryzin and McGill, 2000) represent the primary determination of booking limits using only historical data.

It should be noted that although in some cases models are solved using linear programming logic, this approach cannot be identified with, in particular, because it is necessary to incorporate the entire probabilistic distribution of the demand of a given segment and not just its resulting probability. We would use a purely deterministic approach with this element, but it loses importance and stochastic applications are necessary for the current market reality.

\section{Expected Marginal Seat Revenue model}

The solution of this model is based on the assumption of two different price levels for the same product. So let us assume two levels of value $(\mathrm{V})$ of the same product or service. The model was based only on a higher $(\mathrm{h})$ and lower (I) value level. The following applies:

$V_{h}>V_{l}$.

Knowing these different levels of value, the model can also work with a fair price that corresponds to the given value; therefore, from the perspective of economic theory, the system minimizes the consumer surplus. The following assumption follows:

$D_{l}$ for the number of customers in demand with a lower value,

$D_{h}$ for the number of customers with higher value in demand.

It should be noted that the system does not know the exact distribution of overall market demand, and therefore we are not sure that if we rejected a customer with a value of VI. In other words, we operate with a probability that customers are also in the required amount of DI. The model also works with the concept of expected value (EV), as shown in Eq. 1 and 2:

$\mathrm{EVI}=\mathrm{VI}{ }^{*} \mathrm{PI}(1)$

$\mathrm{EVh}=\mathrm{Vh}$ * $\mathrm{Ph}(2)$

where $\mathrm{Ph}$ and $\mathrm{Pl}$ are the probabilities that a customer with an appropriate value $\mathrm{V}$ will come. Therefore if $\mathrm{PI}=1$, it means that the system is willing to accept a customer with a lower value, but the decision-making process can assume with a certain probability Phthat a customer with a higher value will appear. Littlewood worked with the assumption of the final capacity of possible reservations. This assumption is linked to the second term, the so-called Protection Limit (PLh), which essentially defines the proportion of total capacity (or the number of products/services booked, respectively) defined for customers with a higher level of Vh. From the above, the Littlewood Rule, which addresses the following inequality, can therefore be introduced in Eg. 3.

\section{$V_{l} \geq V_{h} \times P_{h}\left[D_{h}>P L_{h}\right](3)$}

$\mathrm{Ph}$ indicates the probability at which we achieve the Protection Limit PLh value of the total possible demand Dh. If the above condition expressed in the inequality applies, it is preferable to accept the customer's demand with the value $\mathrm{VI}$ with certainty rather than to "wait" to see if the demand with the value Vh will ever be realized. The unknown value in the optimization process is PLh, which indicates how much capacity is advisable to "protect" from the sale and hold it for customers with a higher Vh value.

The EMSR model is an extended model built on Littlewood's rule. The model still aims to establish the exact quantity just as the original rule, but we now assume that the model has $n$ different values that customers are willing to pay at different prices. Therefore, the model assumes $\mathrm{Vn}$ values and therefore $n$ number of customers or a group of customers related to $n$ number of demands. The characteristics of a normal distribution characterize demand.

\section{Extended Expected Marginal Seat Revenue model}

It follows from the above description that the variants of the extension of the original model are pretty modest. In addition, the solution to the problem is the necessary knowledge of operation research. This section of the article presents an extension of the original EMSR model and a solution using the non-linear programming approach using the augmented lagrangian method. 
The primary starting point is that we are looking for a limit value that the company is willing to accept for the reservation provided, at which the customer's lower willingness to pay (WTP) limit with the expected limit value of the customer with higher WTP is at least equal. This expected higher value is based on the assumption of a specific risk that such a customer will not make the reservation (this probability is expressed in the basic model by normal distribution). These calculations aim to establish the so-called Protection Limit, a value that indicates how much free capacity should be available to customers with higher WTP and how many capacities should be offered to customers with lower WTP. Thus, the basic assumption resulting from Littlewood's rule is that a customer with a lower WTP, i.e. with VI, will appear with a probability of one. The whole model thus omits two essential elements. The first consists of so-called no-shows and the second of cancelled reservations. These two elements can be added to the entire model using similar logic from the original EMSR model, namely the addition of the VI probability (the original probability was equal to one, now it will be lower). However, it must be true that the probability associated with a lower WTP was higher than the probability associated with higher WTP (i.e. Vh). Otherwise, the model would lack logic.

The goal is still to determine the Protection Limit value for each segment (there may already be more than two of these segments in EMSR models as foreseen by Littlewood's rule). If we are to provide a mathematical notation of the entire problem required for a non-linear programming solution, then we want to maximize the following purposeful function of determining the EMSR value (for unknown $\mathrm{x}$ ), see Eq. 4:

$$
\begin{aligned}
& \operatorname{EMSR}(\mathrm{x})=\left[1-\left(\int_{-\infty}^{x} \frac{1}{\sigma \times \sqrt{2 \pi}} e^{\frac{(x-\mu)^{2}}{2 \sigma^{2}}} d x\right) \times v_{h}\right] \rightarrow \max (4), \\
& \text { under restrictive conditions (Eq. 5) } \\
& 1-\left(\int_{-\infty}^{x} \frac{1}{\sigma \times \sqrt{2 \pi}} e^{\frac{(x-\mu)^{2}}{2 \sigma^{2}}} d x\right) \times v_{h} \leq v_{l}(5), \\
& \text { conditions of non-compliance } \\
& x \geq 0 .
\end{aligned}
$$

Concerning restrictive conditions, it can also be argued that we are trying to achieve a specific value of the purpose function (namely its value equal to $\mathrm{VI}$ ). However, about the iterative procedure of the solution, a condition of type "less or equal" is more appropriate. This could be the primary solution to finding a protection limit for the original model with a particular VI value and a normal distribution. However, for this article, this model will be extended by a condition that will reflect the so-called no-shows and cancellation of existing reservations for clients with lower WTP (i.e. VI). In a non-linear programming solution algorithm, the same function will be maximized; only the constraint will be extended by a certain selected probability for a customer with lower WTP. The resulting constraint, therefore, looks like Eq. 6:

$$
\begin{aligned}
& {\left[1-\left(\int_{-\infty}^{x} \frac{1}{\sigma_{h} \times \sqrt{2 \pi}} e^{\frac{\left(x-\mu_{h}\right)^{2}}{2 \sigma_{h}^{2}}} d x\right) \times v_{h}\right]-v_{l} \times} \\
& \left(\int_{-\infty}^{x} \frac{1}{\sigma_{l} \times \sqrt{2 \pi}} e^{\frac{\left(x-\mu_{l}\right)^{2}}{2 \sigma_{l}^{2}}} d x\right) \leq 0(6),
\end{aligned}
$$

where indexes $h$ and I indicate variance values, standard deviations and mean values for a customer with a higher and lower willingness to pay. This probability is not computed as a single number but can be solved using the Monte Carlo simulation approach that deals with the random number from the selected probability distribution.

However, it is necessary to add one condition under which the model assumptions must be set, which mentions that the probability must be lower for a customer with a higher WTP. This situation is shown in Eq. 7.

$$
\int_{-\infty}^{x} \frac{1}{\sigma_{h} \times \sqrt{2 \pi}} e^{\frac{\left(x-\mu_{h}\right)^{2}}{2 \sigma_{h}^{2}}} d x<\int_{-\infty}^{x} \frac{1}{\sigma_{l} \times \sqrt{2 \pi}} e^{\frac{\left(x-\mu_{l}\right)^{2}}{2 \sigma_{l}^{2}}} d x(7)
$$

Considering that the EMSR model is solved by comparing all individual pairs with each other, it is necessary to add up the resulting protection limits values for individual segments (or individual pairs of segments), and then the values can be used to get how much of our free capacities we should not offer for sale in the given segments.

The application for revenue managers lies within the extended functionality of the model, which can help them with strategic planning of room sales. While several inputs shape the created strategy, it is crucial to continuously update the model, more precisely the input, to react to the current condition on the market which reflects the basic management cycle.

\section{Discussion}

The above-mentioned extended EMSR model combines several elements and develops more detailed expansion of the MSR model, which can suit better the need for the high quality of revenue managing decisions while reflecting the reality of the hospitality industry and product distribution and taking into account the cancellations and no-shows, which previous researchers omitted. These components have a significant impact on the resulting optimization and must be incorporated into the final solution

Contrary to Tavana \& Weatherford (2019), the study uses non-linear programming, which is somewhat unconventional but necessary since it uses the possibility of understanding the whole model with the assumption of stochastic demand. Moreover, the solution is supported with the Monte Carlo probabilistic simulation that helps to work with the uncertainty.

The model is not focusing on only the variant calculation of the known model like Lawhead \& Gosari (2019) but tried to improve the model results' overall performance, which should be closely connected to market reality.

It is crucial to mention that current research mainly focuses on dynamic pricing(Abrate et al., 2019; Binesh et al., 2021; Vives et al., 2018) while not considering differences in capacity allocation in the market segments. This is mainly caused by the fact thatthe current studies mainly focus on predefined market sub-segment (commonly groups and individual) and do not consider the diversification of the market strategies and their combination. This approach allows the revenue managers to optimize their FIT (Frequent Individual Traveller) strategy while omitting the corporate or group business.

\section{Conclusion}

As mentioned by Ivanov (2020) and Studnicka and Plzakova (2017), researchers must step towards applying their results to hospitality operations. Currently, hoteliers strive to understand better the competitive market and new method to secure the competitive advantage.

While some studies were trying to build the simulationbased models of accommodation facilities(Mariello et al., 2020; Poulova et al., 2019) and used them in revenue managers and student training, e.g. for training and development of tacit knowledge and decision-making procedure, the practitioners strive for accurate data and methodology based models that can not only support but improve the quality of their decision as well.

Within the discussion section, the current pricing (or dynamic pricing) focus is mentioned. The researchers propose to combine the pricing and capacity allocation approaches for a comprehensive understanding of the revenue management decision. On the other hand, the revenue managers are 
commonly using only their tacit knowledge based on their experience, which can hardly predict the fast changes in the market, and any application of the data-based method can improve not only the quality of their decisions but as well the overall performance of the operations while securing the high level of service quality and its perception by the customers.

\section{References}

[1] Abrate, G., Nicolau, J. L., \& Viglia, G. (2019). The impact of dynamic price variability on revenue maximization. Tourism Management, 74

224-233. doi:10.1016/j.tourman.2019.03.013

[2] Binesh, F., Belarmino, A., \& Raab, C. (2021). A meta-analysis of hotel revenue management. Journal of Revenue and Pricing Management, 20(5), 546-558. doi:10.1057/s41272020-00268-w

[3] Büsing, C., Kadatz, D., \& Cleophas, C. (2019). Capacity Uncertainty in Airline Revenue Management: Models, Algorithms, and Computations. Transportation Science, 53(2), 383-400. doi:10.1287/trsc.2018.0829

[4] CROSS, R. (1997). Launching the revenue rocket How revenue management can work for your business. The Cornell Hotel and Restaurant Administration Quarterly, 38(2), 32-43. doi:10.1016/s0010-8804(97)81474-7

[5] Denizci Guillet, B. (2020). An evolutionary analysis of revenue management research in hospitality and tourism. International Journal of Contemporary Hospitality Management, 32(2), 560587. doi:10.1108/ijchm-06-2019-0515

[6] Denizci Guillet, B., \& Mohammed, I. (2015). Revenue management research in hospitality and tourism. International Journal of Contemporary Hospitality Management, 27(4), 526560. doi:10.1108/ijchm-06-2014-0295

[7] Fjälmann, A. (2021, February 2). Revenue Management Data 2021 - No Decision Without Data. Atomize. https://atomize.com/blog/revenue-management-in-2021-nodecision-without-data/

[8] Gönsch, J., Koch, S., \& Steinhardt, C. (2013). An EMSRbased approach for revenue management with integrated upgrade decisions. Computers \& Operations Research, 40(10), 2532-2542. doi:10.1016/j.cor.2013.01.012

[9] Gosavi, A., Ozkaya, E., \& Kahraman, A. F. (2005). Simulation optimization for revenue management of airlines with cancellations and overbooking. OR Spectrum, 29(1), 21-38. doi:10.1007/s00291-005-0018-z

[10] Chiang, W. C., Chen, J. C. H., \& Xu, X. (2007). An overview of research on revenue management: current issues and future research. International Journal of Revenue Management, 1(1), 97. doi:10.1504/ijrm.2007.011196

[11] Ivanov, S. (2014). Hotel revenue management: From theory to practice.

http://search.ebscohost.com/direct.asp?db=hjh\&jid=HOIN\&sco pe $=$ site

[12] Ivanov, S., Del Chiappa, G., \& Heyes, A. (2021). The research-practice gap in hotel revenue management: Insights from Italy. International Journal of Hospitality Management, 95, 102924. https://doi.org/10.1016/j.jijhm.2021.102924

[13] Pereira, L. N. (2016). An introduction to helpful forecasting methods for hotel revenue management. International Journal of Hospitality Management, 58, 13-23. https://doi.org/10.1016/j.ijhm.2016.07.003

[14] Kapichin, O. (2021, Winter). How Can Revenue Managers Improve The Quality Of Their Decisions? | By Oleksii Kapichin. Hospitality https://www.hospitalitynet.org/opinion/4102947.html

[15] Ko, Y. D. (2019). The airfare pricing and seat allocation problem in full-service carriers and subsidiary low-cost carriers. Journal of Air Transport Management, 75, 92-102. doi:10.1016/j.jairtraman.2018.12.003

[16] Koupriouchina, L., van der Rest, J.-P., \& Schwartz, Z. (2014).
On revenue management and the use of occupancy forecasting error measures. International Journal of Hospitality Management, https://doi.org/10.1016/j.ijhm.2014.05.002

[17] Lawhead, R. J., \& Gosavi, A. (2019). A bounded actor-critic reinforcement learning algorithm applied to airline revenue management. Engineering Applications of Artificial Intelligence, 82, 252-262. doi:10.1016/j.engappai.2019.04.008

[18] Mariello, A., Dalcastagné, M., \& Brunato, M. (2020). HotelSimu: Simulation-Based Optimization for Hotel Dynamic Pricing. Learning and Intelligent Optimization, 341-355. doi:10.1007/978-3-030-53552-0_31

[19] Mitra, S. (2007). Revenue management for remanufactured $\begin{array}{lll}\text { products. } & \text { Omega, }\end{array}$ doi:10.1016/j.omega.2005.10.003

[20] Mohsin, A. (2008). How empowerment influences revenue management and service quality: the case of a New Zealand hotel. International Journal of Revenue Management, 2(1), 92. doi:10.1504/ijrm.2008.018180

[21] Noone, B. M., McGuire, K. A., \& Rohlfs, K. V. (2011). Social media meets hotel revenue management: Opportunities, issues and unanswered questions. Journal of Revenue and Pricing Management, 10(4), 293-305. doi:10.1057/rpm.2011.12

[22] Ortega, B. (2016). Revenue management systems and hotel performance in the economic downturn. International Journal of Contemporary Hospitality Management, 28(4), 658-680. doi:10.1108/ijchm-07-2014-0324

[23] Pereira, L. N. (2016). An introduction to helpful forecasting methods for hotel revenue management. International Journal of Hospitality Management, 58, 13-23. doi:10.1016/j.ijhm.2016.07.003

[24] Vulcano, G., van Ryzin, G., \& Chaar, W. (2010). OM Practice-Choice-Based Revenue Management: An Empirical Study of Estimation and Optimization. Manufacturing \& Service Operations Management, 12(3), 371-392. https://doi.org/10.1287/msom.1090.0275

[25] Vulcano, G., van Ryzin, G., \& Chaar, W. (2010). OM Practice-Choice-Based Revenue Management: An Empirical Study of Estimation and Optimization. Manufacturing \& Service Operations Management, 12(3), 371-392. https://doi.org/10.1287/msom. 1090.0275

[26] Vulcano, G., van Ryzin, G., \& Chaar, W. (2010). OM Practice-Choice-Based Revenue Management: An Empirical Study of Estimation and Optimization. Manufacturing \& Service Operations Management, 12(3), 371-392. https://doi.org/10.1287/msom.1090.0275

[27] Studnička, P., \& Plzáková, L. (2017). Connections between scientific research and education in the field of tourism and leisure in the Czech Republic. European Journal of Tourism Research, 15, 24-37.

[28] Vulcano, G., van Ryzin, G., \& Chaar, W. (2010). OM Practice-Choice-Based Revenue Management: An Empirical Study of Estimation and Optimization. Manufacturing \& Service Operations Management, 12(3), 371-392. https://doi.org/10.1287/msom.1090.0275

[29] Vulcano, G., van Ryzin, G., \& Chaar, W. (2010). OM Practice-Choice-Based Revenue Management: An Empirical Study of Estimation and Optimization. Manufacturing \& Service Operations Management, 12(3), 371-392. https://doi.org/10.1287/msom.1090.0275

[30] Verot, B. (2021). How to Choose the Best Revenue Management System for your Hotel. https://www.hotelminder.com/how-to-choose-the-bestrevenue-management-system

[31] Vulcano, G., van Ryzin, G., \& Chaar, W. (2010). OM Practice-Choice-Based Revenue Management: An Empirical Study of Estimation and Optimization. Manufacturing \& Service Operations Management, 12(3), 371-392. https://doi.org/10.1287/msom.1090.0275

[32] Vulcano, G., van Ryzin, G., \& Chaar, W. (2010). OM 


\section{GENERAL MANAGEMENT}

Practice-Choice-Based Revenue Management: An Empirical Study of Estimation and Optimization. Manufacturing \& Service Operations Management, 12(3), 371-392. https://doi.org/10.1287/msom.1090.0275

[33] Vulcano, G., van Ryzin, G., \& Chaar, W. (2010). OM Practice-Choice-Based Revenue Management: An Empirical Study of Estimation and Optimization. Manufacturing \& Service Operations Management, 12(3), 371-392. https://doi.org/10.1287/msom.1090.0275 